In addition to sometimes failing to prevent tetanus both antitoxin and antibiotic may cause hypersensitivity reactions, and the available evidence suggests that horse serum is more dangerous in this respect. Mrs. C. A. Cox and her colleagues, ${ }^{9}$ for example, found that in Britain about $12 \%$ of patients developed a significant reaction to antitoxin. Of the antibiotics which may be used the penicillins are the group most likely to cause trouble, and, though there are no reliable figures of the incidence of reactions in Britain, in the U.S.A. it is perhaps $1 \% .^{10}$ On this evidence, therefore, antibiotics are to be preferred to antitoxin for routine use in Britainthough everyone does not agree with this view. ${ }^{7}$ Even when the antibiotic regimen is preferred there will nevertheless be some wounded patients for whom antitoxin is a wiser choicewhen the wound is over six hours old, and also when the antibiotic possibly may not penetrate into the infected site, as when severe tissue damage is present or when the wound cannot be completely cleaned. ${ }^{3} 5$

A number of antibiotics are suitable for tetanus prophylaxis. If the patient can be trusted to take tablets cloxacillin is a good choice as it is not inactivated by penicillinase, which might be formed in a lesion by bacteria other than Clostridium tetani. $^{5}$ If an injectable prophylactic is preferred a combination of long- and short-acting penicillins is suitable provided the wound is not otherwise infected. E. J. L. Lowbury ${ }^{11}$ recently tested 50 strains of $\mathbf{C l}$. tetani and found that all were fully sensitive to the penicillins and to tetracycline and erythromycin, which also are suitable. Whichever of these antibiotics is used it should be given in full dosage for at least four days-or longer if healing of the wound is delayed, because there is evidence from experiments on animals that shorter periods of treatment can be unreliable. ${ }^{5}$ The local application of antibiotic powder to the wound is worth while, ${ }^{12}$ as there is evidence, again from work on animals, that locally injected antibiotic can be particularly effective. ${ }^{13}$

If antitoxin is preferred for routine use, once again there are some patients for whom it is an unwise choice-those believed to be hypersensitive to horse serum as indicated by a history of previous reactions or a reaction to the trial dose. ${ }^{3}$ The injection of horse serum into a hypersensitive person is not only dangerous but can be valueless, because the serum is likely to be rapidly eliminated from the patient's body; reliance should instead be placed on surgery together with an antibiotic. If, however, as in the case of an extensive, badly soiled wound, antitoxin is considered essential, then every effort should be made to obtain human antitoxin, and small supplies have been made available by the Ministry of Health for this purpose. ${ }^{14}$

In addition to the immediate measures taken for preventing tetanus, all authorities advise that wounded patients should be started on a complete course of immunization with adsorbed toxoid. ${ }^{15}$ Though protection is unlikely to develop for at least four weeks, after this time the patient should need neither antitoxin nor antibiotic if he is again injured.

\footnotetext{
- Cox, C. A., Knowelden, J., and Sharrard, W. J. W., Brit. med. F., 1963, 2, 1360.

10 Van Arsdel, P. P., f. Amer. med. Ass., 1965, 191, 238.

1 Lowbury, E. J. L., in Proceedings of a Symposium on Tetanus in Great Britain, Leeds, 1967, ed. M. Ellis, p. 100.

12 Rubbo, S. D., Lancet, 1966, $2,449$.

12 McDonald, R. T., Chaikof, L., and Truant, J. P., Surg. Gynec. Obstet., 1960, 110, 702.

14 Ministry of Health, Prophylaxis of Rabies and Tetanus, and Treatmen: of Anthrax, Botulism, Organo-phosphorus Poisoning, Snake-bite, and Tetanus, 1967, H.M. (67) 38. London.

18 Principles on Tetanus, Proceedings of the International Conference on
} Tetanus, Berne, 1966, ed. L. Eckmann, p. 576. Berne.

\section{Commonwealth Links}

At a time when the strong but ill-defined bonds between the countries comprising the British Conmonwealth are under stresses of various kinds it is gratifying to note the excellent work being done by the Commonwealth Foundation. Its first report, issued after the initial 18 months of existence, has now appeared.

A registered charity with funds supplied by Commonwealth countries, the Foundation seeks to encourage interchange and co-operation throughout the Commonwealth, especially through the work of professional people in it, as may be seen from its terms of reference:

“( a) To encourage and support fuller representation at conferences of professional bodies within the Commonwealth.

" (b) To assist professional bodies within the Commonwealth to hold more conferences between themselves.

“(c) To facilitate the exchange of visits among professional people, especially the younger element.

“(d) To stimulate and increase the flow of professional information exchanged between the organizations concerned.

" $(e)$ On request to assist with the setting up of national institutions or associations in countries where these do not at present exist.

" $(f)$ To promote the growth of Commonwealth-wide associations or regional Commonwealth associations in order to reduce the present centralization in Britain.

“ $(g)$ To consider exceptional requests for help from associations and individuals whose activities lie outside the strictly professional field but fall within the general ambit of the Foundation's operations as outlined above."

To fulfil its aims the Foundation has been endowed with an annual income of $£ 250,000$, to which all the following Governments subscribe in varying proportions: Britain, Canada, Australia, New Zealand, India, Pakistan, Ceylon, Ghana, Malaysia, Nigeria, Sierra Leone, Tanzania, Cyprus, Uganda, Jamaica, Trinidad and Tobago, Malawi, Zambia, Malta, the Gambia, and Singapore. Guyana subsequently joined the Foundation in December 1966, Barbados in May 1967, and Kenya in July 1967. The chairman is Sir Macfarlane Burnet, O.M., F.R.S., who in 1960 jointly with Professor (now Sir) Peter Medawar, F.R.S., won the Nobel prize for medicine.

So far the Foundation's grants have been made chiefly to professional people, doctors prominently among them, "to attend worth-while conferences at which they can contribute as well as learn." Both the Commonwealth Medical Association and the British Medical Association have been beneficiaries, the latter by a grant to finance the attendance by members of Caribbean Branches at a regional council meeting in Antigua earlier this year. Many other medical organizations have likewise received grants to enable members to attend conferences on special branches of medicine and surgery. Outside medicine the beneficiaries have included engineers, lawyers, accountants, architects, and educationists. Another venture which promises to be helpful is the establishment in developing Commonwealth countries of "professional centres" with a small staff and a library. So far two have been set up-in Kampala, Uganda, and Port-of-Spain, Trinidad. The aim is that these premises shall be available for professional meetings and lectures.

In fostering professional relations within the Commonwealth the Foundation is helping to bring peace and prosperity to a world badly in need of both. And with a tradition that pays little heed to national frontiers doctors in particular will feel grateful to the Commonwealth Governments for setting up this worth-while organization. 